\title{
Aplicação de Métodos Numéricos e Analítico na Solução de Um Problema de Deflexão em Vigas
}

\author{
Adriana Martins \\ Ana Raíza Ciscoto Yoshioka \\ Guilherme Bertuzzo Lima \\ Coordenação de Engenharia Civil, COECI, UTFPR-CM \\ 87301-899, Campo Mourão, PR \\ E-mail: adriana.martins77@yahoo.com.br,raiza.11@gmail.com, guiberlim@hotmail.com
}

\section{Adilandri Mércio Lobeiro}

Departamento de Matemática, DEMAT, UTFPR-CM

87301-899, Campo Mourão, PR

E-mail: alobeiro@utfpr.edu.br

\author{
Eloy Kaviski Liliana Madalena Gramani \\ Departamento de Hidráulica e Saneamento, DHS, UFPR \\ Departamento de Matemática, DMAT, UFPR \\ 81531-970, Campus Politécnico, Curitiba, PR \\ E-mail: eloy.dhs@ufpr.br, gramani@mat.ufpr.br
}

\section{RESUMO}

A equação diferencial da linha elástica para uma viga em balanço, sujeita a uma carga pontual aplicada em sua extremidade é

$$
E I \frac{d^{2} y}{d x^{2}}=-P(L-x)
$$

onde $L$ é o comprimento da viga, $E$ é o módulo de elasticidade e $I$ é momento de inércia [3] . Relacionando as condições $y(0)=0$ e $y(L)=v_{\text {máx }}=-P L^{3} / 3 E I$, obtém-se o Problema de Valor de Contorno (PVC)

$$
\mid \begin{gathered}
E I \frac{d^{2} y}{d x^{2}}=-P(L-x) \\
y(0)=0 \quad, \quad y(L)=-\frac{P L^{3}}{3 E I} .
\end{gathered}
$$

Para um estudo de caso, considera-se $E=30000 \mathrm{ksi}, I=800 \mathrm{in}^{4}, P=1$ kip e $L=10$ pés [2] . O objetivo deste trabalho é obter as soluções analítica e numérica do PVC

$$
\begin{aligned}
\frac{d^{2} y}{d x^{2}} & =\frac{x-10}{24000000} \\
y(0)=0 & , \quad y(10)=-\frac{1}{72000} .
\end{aligned}
$$

A solução analítica para o PVC (3) é

$$
y(x)=\frac{-10 x^{2}}{48000000}+\frac{x^{3}}{144000000} .
$$

Para obter a solução numérica do PVC (3), foi aplicado o Método das Diferenças Finitas (MDF), substituindo as derivadas da equação diferencial pelas fórmulas de diferenças centradas obtendo a equação

$$
-y_{i-1}+2 y_{i}-y_{i+1}=-h^{2}\left(\frac{x_{i}-10}{24000000}\right),
$$


onde $y_{i} \approx y\left(x_{i}\right)$ para $i=1,2, \cdots, N$. Para isso, escolheu-se um número inteiro $N=19$ e dividiu-se o intervalo $[0 ; 10]$ em 20 subintervalos de mesmo comprimento cujos extremos são os pontos da malha $x_{i}=i h$ para $i=0,1,2, \cdots, 20 \operatorname{com} h=0.5$. Fazendo $i=1,2, \cdots, 19$ na equação (5) e utilizando as condições de contorno $y_{0}=0$ e $y_{20}=-1 / 72000$ obtém-se um sistema de equações lineares que, quando expresso na forma matricial, apresenta uma matriz de coeficentes tridiagonal de ordem $19 \times 19$ [1]. Para resolver esse sistema, utilizou-se o software Maple, encontrando a solução numérica do PVC (3).

A Tabela 1 apresenta uma comparação para alguns dos pontos calculados.

Tabela 1: Comparação entre as Soluções Analítica e Numérica

\begin{tabular}{ccccc}
\hline $\mathrm{i}$ & $x_{i}$ & Numérica & Analítica & Erro Percentual \\
\hline 0 & 0 & 0 & 0 & - \\
1 & 0,5 & $-5,121527774 \cdot 10^{-8}$ & $-5,121527777 \cdot 10^{-8}$ & 0,000000058576273 \\
4 & 2,0 & $-7,777777777 \cdot 10^{-7}$ & $-7,777777778 \cdot 10^{-7}$ & 0,000000012857139 \\
8 & 4,0 & $-2,888888889 \cdot 10^{-6}$ & $-2,888888889 \cdot 10^{-6}$ & 0,000000000000000 \\
12 & 6,0 & $-6,000000000 \cdot 10^{-6}$ & $-6,000000000 \cdot 10^{-6}$ & 0,000000000000000 \\
16 & 8,0 & $-9,777777778 \cdot 10^{-6}$ & $-9,777777778 \cdot 10^{-6}$ & 0,000000000000000 \\
20 & 10 & $-1 / 72.000$ & $-1 / 72.000$ & - \\
\hline
\end{tabular}

A Figura 1 apresenta os gráficos das soluções analítica e numérica.

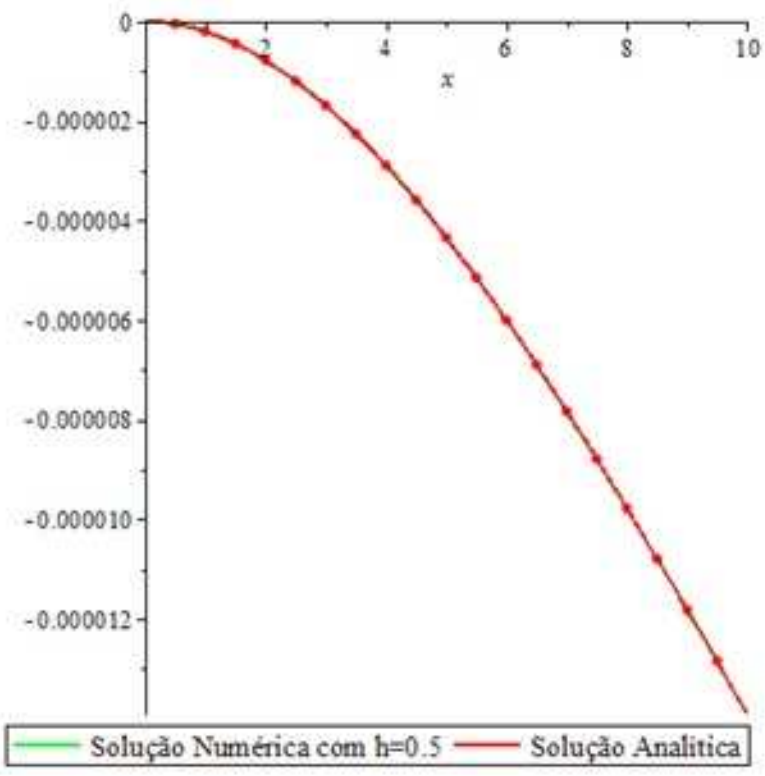

Figura 1: Função Da Linha Elástica

Com base na Tabela 1 e Figura 1 conclui-se a eficiência do MDF.

Palavras-chave: Diferenças Finitas, Deflexão de viga, Equações Diferenciais

\section{Referências}

[1] R. L. Burden, D. J. Faires, “Análise Numérica, $1^{a}$ Edição, São Paulo, Editora Thomson, 2003.

[2] S. C. Chapra, "Métodos numéricos para engenharia", 5. ed, São Paulo, SP: McGraw-Hill, 2008

[3] R. C. Hibbeler "Resistência dos materiais", 7. ed, São Paulo, SP: Pearson, 2010. . 